\title{
Etiology and Management of Complications Associated with Sinus Augmentation Procedures
}

\author{
Santhosh B. Shenoy ${ }^{1}$ Avaneendra Talwar ${ }^{1} \quad$ Smitha Shetty ${ }^{1} \quad$ Raghavendra Vamsi Anegundi ${ }^{1}$ \\ ${ }^{1}$ Department of Periodontics, A.B. Shetty Memorial Institute of \\ Dental Sciences, Nitte (deemed to be) University, Derlakatte, \\ Mangaluru, Karnataka, India

\begin{abstract}
Address for correspondence Raghavendra Vamsi Anegundi, BDS, Department of Periodontics, A.B. Shetty Memorial Institute of Dental Sciences, Nitte (deemed to be) University, Derlakatte, Mangaluru 575018, Karnataka, India (e-mail: arvamsi2009@gmail.com).
\end{abstract}

\begin{abstract}
Keywords

- complications

- membrane tear

- bleeding

- sinus augmentation

- implant

Sinus floor elevation is a predictable procedure for vertical bone augmentation in the atrophic posterior maxilla. As with most surgical procedures, complications can be encountered during sinus floor elevation/augmentation. A clinician should have a thorough knowledge of factors that can lead to complications and possible ways to manage. Presurgical evaluation of the sinus is a prerequisite in identifying the concomitant presence of systemic disease and maxillary sinus disease that may lead to postoperative complications. Despite the best efforts, one may encounter adverse events. Complications can broadly be divided into intraoperative, acute, and chronic complications based on the timing of its occurrence. The most commonly encountered complications include membrane perforation and excessive bleeding. Evaluation of anatomic deviations and sound surgical skill is required to reduce intraoperative complications. Prevention is better than cure. It is always better to know how and when a complication might occur so that the clinician might take the necessary steps to avoid it. This article reviews the management of most commonly encountered complications and the best possible ways to manage them.
\end{abstract}

\section{Introduction}

The alteration in alveolar bone dimension (vertical and horizontal) following tooth loss in the posterior dental arches makes it challenging to accommodate dental implants. In such situations, clinicians choose to replace the lost teeth using short implants, tilted implants, zygomatic implants, or conventional implants with sinus augmentation. Sinus augmentation had a better prognosis compared with all other available procedures to rehabilitate severely deficient alveolar bones. ${ }^{1}$ The sinus augmentation is a well-documented bone augmentation procedure to gain the vertical height. Studies have proven a high success rate for implants in combination with sinus elevation. However, with an increasing number of clinicians performing them and an increasing

published online February 10, 2021
DOI https://doi.org/ 10.1055/s-0041-1723052 ISSN 2582-4287. number of cases, surgical (intraoperative) and postsurgical complications have also increased. Sinus elevation is considered a relatively invasive procedure with a low incidence of complications, intraoperatively and postsurgically. Most complications reported in literature can be avoided by careful and precise presurgical evaluation of the sinus. The most common type of complication reported with sinus floor elevation is the perforation of the Schneiderian membrane. ${ }^{2}$

Case selection is the first step toward success for any surgical procedure. The sinus augmentation is generally indicated in residual ridges with inadequate width to place implants conventionally or in the atrophic maxilla or when there is a low quality of available bone. The absolute and relative sinus contraindications are listed in $\boldsymbol{-}$ Table $1 .^{3}$ Uncontrolled

(C) 2021. Nitte (Deemed to be University).

This is an open access article published by Thieme under the terms of the Creative Commons Attribution-NonDerivative-NonCommercial-License, permitting copying and reproduction so long as the original work is given appropriate credit. Contents may not be used for commercial purposes, or adapted, remixed, transformed or built upon. (https://creativecommons.org/licenses/by-nc-nd/4.0/).

Thieme Medical and Scientific Publishers Pvt. Ltd. A-12, 2nd Floor, Sector 2, Noida-201301 UP, India 
Table 1 Contraindications for maxillary sinus augmentation ${ }^{3}$

\begin{tabular}{|c|c|}
\hline Absolute contraindications & Relative contraindications \\
\hline $\begin{array}{l}\text { 1. Posttraumatic/surgical/radiotherapy scarring on the } \\
\text { nasal-sinus walls and/or mucosa lining }\end{array}$ & $\begin{array}{l}\text { 1. Stenosis of drainage pathways in sinus (septal deviation, presence } \\
\text { of Haller cell, paradox curve of middle turbinate bone, oroantral } \\
\text { fistula, etc.) }\end{array}$ \\
\hline 2. Recurring or chronic sinusitis with or without polyps & $\begin{array}{l}\text { 2. Acute viral or bacterial or mycotic or allergic rhinosinusitis } \\
\text { (functional endoscopy indicated) }\end{array}$ \\
\hline 3. Intolerance to acetylsalicylic acid & $\begin{array}{l}\text { 3. Nonobstructive benign tumors, mucosal cysts, cholesterinic } \\
\text { granuloma, antrochoanal polyp (functional endoscopy required) }\end{array}$ \\
\hline \multicolumn{2}{|l|}{ 4. Immunological deficiencies } \\
\hline \multicolumn{2}{|l|}{ 5. Wegener's granulomatosis, sarcoidosis } \\
\hline \multicolumn{2}{|l|}{$\begin{array}{l}\text { 6. Locally aggressive benign tumors (myxoma, inverted } \\
\text { papilloma) }\end{array}$} \\
\hline 7. Nasal-sinus malignant tumors of the maxillary sinus & \\
\hline
\end{tabular}

systemic conditions, smoking, and preoperative sinus pathologies, if not appropriately managed, can lead to acute complications postoperatively. ${ }^{4}$ A thorough preoperative evaluation of the sinus with adequate knowledge about the sinus anatomy and its common variations is needed to avoid most complications at any stage of the procedure. Before the procedure, most of the complications mentioned above can be avoided by careful evaluation by cone beam computed tomography (CBCT) and ENT clearance.

\section{Etiology of Sinus Complications}

The etiology of complications is listed in - Table 2. Apart from the previously mentioned sinus-related contraindications, the contraindications to implant surgery or periodontal or conventional surgeries will become apparent contraindications for sinus surgery, for example, systemic conditions like uncontrolled diabetes or any other immunocompromised conditions. Uncontrolled diabetes has been linked with increased susceptibility to complications or infections because of the reduced host response, lowered chemotaxis, and phagocytosis of early responding polymorphonuclear leukocytes. ${ }^{5,6}$ During sinus elevation, uncontrolled diabetes may contribute to decreasing graft turnover, postoperative infection, and cause the incision line opening. Although no studies have assessed the influence of diabetic control on sinus augmentation, researches have shown no significant influence on implant outcomes. ${ }^{7}$ However, due to the proximity to the maxillary sinus, which can be predisposed to congestion and irritation, infection in the sinus may be more notable than after routine implant placement.

Another condition that should be addressed and managed with attention is osteoporosis and its associated medicine, that is, bisphosphonate. It was found that patients under bisphosphonate therapy experienced 40 to $46 \%$ implant loss following their induction into grafted sinuses. ${ }^{8}$ To allow for proper healing of the graft following sinus augmentation, prolonging the healing time before implant placement has been suggested. In the maxilla, 8 months should be given for graft maturation, whereas in the mandible, at least 6 months is advised. ${ }^{9}$
Patients with immunocompromised states are often contraindicated for sinus augmentation because of the impaired wound healing, prospect of infection, and altered bone metabolism. Generally, the amount of literature contraindicating sinus augmentation and implant therapy due to systemic diseases is low.

Cigarette smoking has shown to significantly increase the rate of complications in dental therapy. ${ }^{10,11}$ Although the definite mechanism is not clearly understood, the impaired immune response and vascular changes observed among smokers have been thought to play a significant role. It was observed that smoking increases the implant failure by 7.0 to $17.1 \%$, and it has also been found that smoking significantly increases the failure rate (12.7\%) compared with nonsmokers ${ }^{12}$ (4.8\%). Smokers also have a significantly higher prevalence of acute infections at $14.2 \%$ than in nonsmokers (2.2\%). ${ }^{13}$

The most common complications associated with antral lift are perforation or tear (60\%), infection (21\%), bleeding (9\%), dislocation of the implant into the sinus, and rarely benign paroxysmal position vertigo (BPPV). ${ }^{2}$ The first mentioned complications are generally encountered intraoperatively, while the latter two complications are commonly seen postoperatively. Intra and postoperative complications are listed in - Table 3 . $^{14}$

\section{Intraoperative Complications}

\section{Membrane Perforation}

It is the most frequent type of complication concerning maxillary sinus elevation. Various factors accentuate the chances of membrane perforation. The tear of the membrane can occur at any stage of sinus elevation, such as during the lateral wall scoring or elevation of bony walls or when releasing the membrane. ${ }^{15}$ Perforation may also occur when there is a pre-existing perforation, existing, or previous pathology. Such factors can be eliminated with proper history taking and systematic evaluation of radiographs. The prognosis of the treatment generally depends on the amount of membrane tear. ${ }^{16}$ It is observed that when the membrane tear is less than $5 \mathrm{~mm}$, the survival rate of implants is around $97.14 \%, 5$ to $10 \mathrm{~mm}$ of tear has a $91.89 \%$ of survival rate and when it is $10 \mathrm{~mm}$ or more, the survival rate is 
Table 2 Classification of complications based on etiology ${ }^{13}$

\begin{tabular}{|c|c|c|c|c|}
\hline $\begin{array}{l}\text { Pre-existing systemic } \\
\text { diseases and medications } \\
\text { related }\end{array}$ & $\begin{array}{l}\text { Anatomy and surgical } \\
\text { procedure-related }\end{array}$ & $\begin{array}{l}\text { Sinus pathology } \\
\text { related }\end{array}$ & Infection-related & Prosthetic related \\
\hline Uncontrolled diabetes & Perforation of membrane & Pseudocysts & Infection & $\begin{array}{l}\text { Postoperative temporary } \\
\text { prosthesis }\end{array}$ \\
\hline Osteoporosis & Sinus septa & Retention cysts & Swelling/hematoma & $\begin{array}{l}\text { Implant length and } \\
\text { diameter }\end{array}$ \\
\hline Bisphosphonate medication & $\begin{array}{l}\text { Onlay graft and residual } \\
\text { bone height }\end{array}$ & Mucoceles & $\begin{array}{l}\text { Incision line } \\
\text { opening/ wound } \\
\text { dehiscence }\end{array}$ & $\begin{array}{l}\text { Insufficient number of } \\
\text { implants }\end{array}$ \\
\hline $\begin{array}{l}\text { Immunocompromised } \\
\text { patients }\end{array}$ & Bleeding & & $\begin{array}{l}\text { Bone sequestrum/ } \\
\text { fragments }\end{array}$ & Increased occlusal table \\
\hline \multirow[t]{2}{*}{ Cigarette smoking } & $\begin{array}{l}\text { Displacement of implants } \\
\text { into sinus }\end{array}$ & & Sinusitis & Nonsplinted implants \\
\hline & Obliteration of sinus cavity & & Oroantral fistula & \\
\hline
\end{tabular}

Table 3 Classification of complications based on time of occurance ${ }^{14}$

\begin{tabular}{|l|l|l|}
\hline Intraoperative & Acute postoperative & $\begin{array}{l}\text { Chronic } \\
\text { postoperative }\end{array}$ \\
\hline $\begin{array}{l}\text { Tearing of } \\
\text { membrane/ nasal } \\
\text { Penetration }\end{array}$ & $\begin{array}{l}\text { Pain, swelling, edema, } \\
\text { Infection }\end{array}$ & Infection \\
\hline Bleeding & Acute Sinusitis & Chronic sinusitis \\
\hline $\begin{array}{l}\text { Obstruction of } \\
\text { ostium }\end{array}$ & Hemosinus & $\begin{array}{l}\text { Implant periapi- } \\
\text { cal lesion }\end{array}$ \\
\hline $\begin{array}{l}\text { Insufficient pri- } \\
\text { mary stability }\end{array}$ & Oroantral fistula & $\begin{array}{l}\text { Postoperative } \\
\text { maxillary cyst }\end{array}$ \\
\hline $\begin{array}{l}\text { Fenestration/ } \\
\text { dehiscence }\end{array}$ & $\begin{array}{l}\text { Benign paroxysmal } \\
\text { positional vertigo }\end{array}$ & $\begin{array}{l}\text { Temporary or perma- } \\
\text { nent palatal numbness }\end{array}$ \\
\hline $\begin{array}{l}\text { Perforation of } \\
\text { alveolar bone }\end{array}$ & & \\
\hline
\end{tabular}

around $74.14 \% .{ }^{17}$ The decision making of implant placement is generally up to the clinician's experience, but the literature suggests $\sim 90.81 \%$ of survival rate when a contemporary approach is used. ${ }^{16}$ So, a careful and wise decision has to be made when perforation occurs. A staged approach is a safe method as it gives time for the membrane to heal. Classification of membrane perforations is given in - Table 4. $^{18,19}$

\section{Management}

It is a well-established fact that membrane perforation is commonly encountered during direct sinus lift procedures than indirect sinus lift. The access to the membrane is generally substantial with direct sinus lift than in indirect where it is minimal. Hence, it becomes evident that management with different approaches is different. In either of the cases, verifying membrane integrity plays an important role. Endoscopic examination of the sinus is the gold standard, while there are few other procedures such as Valsalva maneuver, microscopic examination, and sterile saline washings. It is perceived that implants' success rate is generally high in nonperforated areas (100\%) to perforated areas (69.56\%). ${ }^{16} \mathrm{By}$ using any of the techniques mentioned earlier, the amount
Table 4 Classification of membrane perforation ${ }^{18,19}$

\begin{tabular}{|l|l|}
\hline $\begin{array}{l}\text { Type of } \\
\text { perforation }\end{array}$ & Extent of perforation \\
\hline $\begin{array}{l}\text { Class I } \\
\text { perforation }\end{array}$ & $\begin{array}{l}\text { Perforation occurring at any point along } \\
\text { the most apical wall of the prepared sinus } \\
\text { window }\end{array}$ \\
\hline $\begin{array}{l}\text { Class II } \\
\text { perforation }\end{array}$ & $\begin{array}{l}\text { Perforations occurring along with the lateral } \\
\text { or crestal aspects of the prepared sinus } \\
\text { window }\end{array}$ \\
\hline $\begin{array}{l}\text { Class III } \\
\text { perforation }\end{array}$ & $\begin{array}{l}\text { Perforations occurring at any location within } \\
\text { the body of the prepared sinus window }\end{array}$ \\
\hline
\end{tabular}

of perforation has to be determined. The amount of perforation directly correlates with the prognosis of implants to be placed. Small perforations (1-2 $\mathrm{mm}$ ) generally do not need any attention; they heal by themselves. However, when perforations are large, surgery is deemed an absolute contraindication and should plan a staged approach. ${ }^{20}$ Nevertheless, some authors suggest a contemporary approach even with perforation with higher failure rates. Large membrane perforations have to be managed using a lateral approach only. The basic principle of treating perforations is to isolate the membrane from the surrounding tissues or graft particles. When perforations are below $5 \mathrm{~mm}$, the membrane can be sutured, or a resorbable membrane can be placed between the membrane and the bone graft. If the perforation is between 5 and $10 \mathrm{~mm}$, the resorbable membrane is used, and a small part of the lamellar bone from the sinus window is utilized to reinforce the reconstruction before placing the grafting material. Large perforations or perforations $>10 \mathrm{~mm}$ are managed in either of three ways: (1) Covered with the lamellar bone of the sinus window, (2) covered with a pedicled buccal fat pad, (3) by the placement of a bone block graft harvested from intraoral sites. Platelet-rich fibrin was also used successfully instead of collagen membrane in treating membrane tears because of its cost-effectiveness and ease of manipulation. ${ }^{16}$ Nevertheless, when the implant depth inside the maxillary sinus is higher ( $>2 \mathrm{~mm}$ ), the sinus membrane does not repair immediately, and debris concentrates on the exposed surfaces of the implants that were not covered by 
native bone inside the sinus cavity, which could lead to sinusitis. ${ }^{21}$ This might lead to bone graft failure, which might eventually lead to the implant's failure. Membrane perforations generally do not lead to chronic postoperative complications.

\section{Bleeding}

The infraorbital and posterior superior alveolar artery runs in and out of the maxillary sinus lateral wall, forming an extraosseous and intraosseous anastomosis. For the intraosseous branch, it has been stated that straight type branching is present in $75 \%$ of cases, and U-shaped branching is seen in $\sim 25 \%$ of cases. It is to be perceived that only a part of intraosseous branching is seen in CBCT; it is possible to predict blood vessels' paths, which again is a part of the pre-surgical evaluation. The intraosseous branch can be approximately located in the $\mathrm{CBCT}$ from fixed landmarks. The distance from cementoenamel junction of posterior maxilla to vessel ranges from 15.2 to $34.6 \mathrm{~mm}$ with an average of 21.1 to $26.9 \mathrm{~mm}$. The distance of vessels from the maxillary sinus's inferior border ranges from 2.5 to $19.4 \mathrm{~mm}$ with an average of 9.4 to $10.3 \mathrm{~mm} .{ }^{22}$ Assigning the above-mentioned measurements into clinical practice, it is safe to place the windows' borders as low as possible, therefore lessening the chances of encountering the intraosseous branch.

\section{Management}

As with the bleeding at other sites, pressure must be applied at the bleeding site, and the patient should be advised to lift his head. When there is no pulse rhythm in the intraosseous branch, bleeding can be controlled with gauze packing. If bleeding does not stop, electrocoagulation, laser, or hemostat can be used to control bleeding. As a last resort, bone rongeur can crush the bone at the site, hence controlling bleeding. A high-speed handpiece can be fitted with a diamond bur and applied to the bleeding site without irrigation to control bleeding. Bone wax is also useful in the management of bleeding. ${ }^{23}$

\section{Postoperative Complications \\ Acute Complications}

Acute complications generally occur within 24 hours to few weeks of surgery. Typical symptoms include foul odor, migraine type of headache, midfacial discomfort, pressure with head position, tenderness, and nasal obstruction. In the case of sinus infection, purulent nasal exudate is seen in addition to the symptoms mentioned above. For the management of sinus infection or sinusitis, antibiotics should be prescribed for 2 weeks along with nasal decongestant, antihistamines, analgesics, and patients should be encouraged to inhale steam to eliminate the excess secretions. The antibiotic of choice for sinus infection is Augmentin (500 mg amoxicillin and $125 \mathrm{mg}$ of clavulanic acid). If the symptoms are not relieved by medication or the patient develops symptoms spontaneously, a surgical approach must be initiated. A small incision is placed on the lateral wall, and the flap is elevated, and bur is used to pierce the wall. Generally, an 18-gauze syringe is used to aspirate the contents inside the cavity. After instructing the patient to hold his breath, normal saline or saline solution with antibiotics is introduced into the maxillary sinus, and aspiration is executed again. If saline leaks out of the patient's mouth or nose, the patient should be advised to sit in an upright position. Suturing is generally unnecessary, and the procedure should be repeated regularly, which might require patients to visit the clinic every day until symptoms are relieved. If symptoms do not get relived, patients have to be referred to ENT specialists, and the patient might have to undergo functional endoscopic sinus surgery. ${ }^{23}$

BPPV may occur while using a mallet in the osteotome technique to elevate the sinus. This occurs when otoliths in the utricular macula are detached by the impact of malleting and move each time the patient changes position, causing dizziness. The patient should be informed about the risk of BPPV before surgery if osteotome is planned. It generally occurs in patients above 50 years, and incidence increases with age. Epley maneuver has to be performed when symptoms of BPPV occur. It is a method of changing the patient's position and head direction, causing displaced otoliths to come back to the original position. ${ }^{24}$

\section{Chronic Complications}

Implant periapical lesion is one complication that is encountered apart from the complications mentioned above, which is rare. It occurs due to excessive heat generated during the drilling procedure. This can be controlled by using an adequate amount of chilled saline for irrigation. An internal irrigation drill can prevent a temperature rise inside the bone, but it is difficult to clean and disinfect since the tube is narrow. However, it is comfortable and practical to perform irrigation at the drilling site using a syringe. ${ }^{24}$

Chronic sinusitis is generally seen in patients with oversized turbinates and septal deviation. This can be avoided by careful and systemic presurgical evaluation of sinus, and it is thought to be a contraindication of sinus augmentation. Sinus membrane thickening is also thought to be a prerequisite for postoperative chronic sinusitis. Patients with a history of sinusitis have higher chances of postoperative complications. Hence, patients have to undergo a nasal-endoscopic evaluation to rule out the presence of obstructive phenomena. Idiopathic neuralgia of maxilla is a rare finding that occurs postoperatively.

\section{Prosthetic Complications}

Though these are also a cause for complications, these have been discussed separately. Though they do not cause complications immediately, they certainly hamper or alter the long-term survival and/or success of the implants. Proper presurgical prosthetic planning is required for implants' success before placing implants with or without sinus elevation procedure. Emphasis has to be given for prosthetically driven placement of implants. Bone grafting and sinus elevation should follow the prosthodontic design. Postoperative temporary restoration plays a significant role in shaping soft tissue and securing the grafted particles around the implant. The caution has to be taken not to load these prostheses. 
Partial or full dentures can cause excessive pressure at the augmented site, if not relieved properly. This excessive pressure may lead to dehiscence, soft tissue complications, and failure of the graft. Dislocation of the implant into the antrum can also occur, as mentioned above.

The posterior maxilla is ten times less dense than the posterior mandible. ${ }^{25}$ Restorations planned in these regions must maintain proper biomechanics to maintain health and avoid unfavorable crestal bone loss. Osseointegration in such low-density areas is less predictable than the denser areas in mandible. ${ }^{26}$ Hence, to maximize the bone-implant contact, large-diameter implants are chosen than longer implants, as they have shown better results. Increasing the number of implants in the posterior maxilla has a better long-term success rate. Splinting of implants should be considered whenever possible, as they have better stress distribution than nonsplinted ones. ${ }^{27}$ Generally, a reduced occlusal table is preferred, eliminating excursive and nonworking contacts, which reduces the strain on the bone. If appropriate principles are not followed, implant displacement into the sinus will increase drastically, leading to complex surgical procedures. ${ }^{28}$ Retrieval of displaced implants from the antrum generally requires endoscopy or Cadwell-Luc approach. Emphasis has to be given to reduce the bending movements on implants as far as possible. It was determined that decreased bending of implants could be accomplished with prosthetically driven implant placement, narrow occlusal surfaces, splinted implants, and occlusal contacts that provide for axial loading, thus reducing the offset forces. ${ }^{13}$

Clinical recommendations to limit intra- and postoperative complications are as follows ${ }^{3}$ :

1. Thorough evaluation of the medical history of the patient.

2. Preoperative computed tomography scan to evaluate sinus anatomy and identify preexisting pathology.

3. Proper patient selection stressing a healthy maxillary sinus.

4. A smoking-cessation protocol is always recommended and, especially in the case of heavy smokers ( $\geq 15$ cigarettes a day), this should be evaluated with caution

5. Resolution of periodontal and/or endodontic diseases.

6. Adequate antibiotic prophylaxis

7. Achieve full-mouth plaque score and full-mouth bleeding score of $<15 \%$ before planning for surgery. In the case of provisional crowns, it is advisable to remove the temporary crowns and disinfect the abutments with an antiseptic solution.

8. Preoperative disinfection of the skin with an antiseptic solution and mouth rinses with chlorhexidine.

9. Use of sterile draping and infection-control protocol.

10. Keep the incisions distant from the antrostomy.

11. Prevent salivary contamination of bone graft and/or other biomaterials.

12. Intra- and postoperative control of the hemostasis.

13. Prevention of bone overheating.
14. Use of two different sets of surgical instruments: one for the flap-elevation phase and the other for the grafting.

15. Rinsing the operative field with sterile saline solution.

16. Managing the surgical time as short as possible.

17. Postsurgical oral rinses with chlorhexidine.

18. Correct postoperative drug therapy.

19. Preplanned check-ups: weekly for the first month and monthly for the following 3 months

\section{Conclusion}

Prevention is better than cure. Managing complications is a tenacious process that is physically, psychologically, and financially draining for patients. Hence, it is better to avoid complications as much as possible. This can be accomplished by a thorough understanding of the sinus's anatomy, the patient's medical status, presurgical evaluation of the sinus, and precise planning of surgery along with proper communication with the patient.

\section{Conflict of Interest}

None declared.

\section{References}

1 Balaji SM, Balaji P. Comparative evaluation of direct sinus lift with bone graft and zygoma implant for atrophic maxilla. Indian J Dent Res 2020;31(3):389-395

2 Barone A, Santini S, Sbordone L, Crespi R, Covani U. A clinical study of the outcomes and complications associated with maxillary sinus augmentation. Int $\mathrm{J}$ Oral Maxillofac Implants 2006;21(1):81-85

3 Testori T, Weinstein T, Taschieri S, Wallace SS. Risk factors in lateral window sinus elevation surgery. Periodontol 2000 2019;81(1):91-123

4 Larkin JG, Frier BM, Ireland JT. Diabetes mellitus and infection. Postgrad Med J 1985;61(713):233-237

5 Wilson RM. Neutrophil function in diabetes. Diabet Med 1986;3(6):509-512

6 Geerlings SE, Hoepelman AI. Immune dysfunction in patients with diabetes mellitus (DM) FEMS Immunol Med Microbiol 1999;26(3-4):259-265

7 Fiorellini JP, Chen PK, Nevins M, Nevins ML. A retrospective study of dental implants in diabetic patients. Int J Periodontics Restorative Dent 2000;20(4):366-373

8 Blomqvist JE, Alberius P, Isaksson S, Linde A, Hansson BG. Factors in implant integration failure after bone grafting: an osteometric and endocrinologic matched analysis. Int J Oral Maxillofac Surg 1996;25(1):63-68

9 Fujimoto T, Niimi A, Nakai H, Ueda M. Osseointegrated implants in a patient with osteoporosis: a case report. Int J Oral Maxillofac Implants 1996;11(4):539-542

10 Schwartz-Arad D, Herzberg R, Dolev E. The prevalence of surgical complications of the sinus graft procedure and their impact on implant survival. J Periodontol 2004;75(4):511-516

11 McDermott NE, Chuang SK, Woo VV, Dodson TB. Complications of dental implants: identification, frequency, and associated risk factors. Int J Oral Maxillofac Implants 2003;18(6):848-855

12 Jensen OT, Shulman LB, Block MS, Iacono VJ. Report of the sinus consensus conference of 1996. Int J Oral Maxillofac Implants 1998;13(Suppl):11-45 
13 Katranji A, Fotek P, Wang HL. Sinus augmentation complications: etiology and treatment. Implant Dent 2008;17(3):339-349

$14 \mathrm{Kim} \mathrm{J}$, Jang H. A review of complications of maxillary sinus augmentation and available treatment methods. J Korean Assoc Oral Maxillofac Surg 2019;45(4):220-224

15 Kim JH, Kim UC, Lee JY, Kim HC, Kim SN. A clinical \& radiologic study of bone remodeling effects using rhBMP-2 for maxillary sinus graft. J Dent Implant Res 2016;35:46-52

16 Hernández-Alfaro F, Torradeflot MM, Marti C. Prevalence and management of Schneiderian membrane perforations during sinus-lift procedures. Clin Oral Implants Res 2008;19(1):91-98

17 Kim YK, Kim JA. Evaluation of factors which affect the prognosis of sinus bone graft and implant placement. J Dent Implant Res 2012;31:31-37

18 Fugazzotto PA, Vlassis J. A simplified classification and repair system for sinus membrane perforations. J Periodontol 2003;74(10):1534-1541

19 Vlassis JM, Fugazzotto PA. A classification system for sinus membrane perforations during augmentation procedures with options for repair. J Periodontol 1999;70(6):692-699

20 Pikos MA. Maxillary sinus membrane repair: update on technique for large and complete perforations. Implant Dent 2008;17(1):24-31

21 Ragucci GM, Elnayef B, Suárez-López Del Amo F, Wang HL, Hernández-Alfaro F, Gargallo-Albiol J. Influence of exposing dental implants into the sinus cavity on survival and complications rate: a systematic review. Int J Implant Dent 2019;5(1):6

22 Ella B, Sédarat C, Noble RdaC, et al. Vascular connections of the lateral wall of the sinus: surgical effect in sinus augmentation. Int J Oral Maxillofac Implants 2008;23(6):1047-1052

23 Pignataro L, Mantovani M, Torretta S, Felisati G, Sambataro G. ENT assessment in the integrated management of candidate for (maxillary) sinus lift. Acta Otorhinolaryngol Ital 2008;28(3):110-119

24 Peñarrocha-Diago M, Maestre-Ferrín L, Cervera-Ballester J, Peñarrocha-Oltra D. Implant periapical lesion: diagnosis and treatment.MedOralPatolOralCirBucal2012;17(6):e1023-e1027

25 Misch CE, Wang HL. Immediate occlusal loading for fixed prostheses in implant dentistry. Dent Today 2003;22(8):50-56

26 Misch CE, Contemporary Implant Dentistry St. Louis: Mosby-Year Book, Inc; 1993

27 Guichet DL, Yoshinobu D, Caputo AA. Effect of splinting and interproximal contact tightness on load transfer by implant restorations. J Prosthet Dent 2002;87(5):528-535

28 Cehreli MC, Iplikçioglu $\mathrm{H}$. In vitro strain gauge analysis of axial and off-axial loading on implant supported fixed partial dentures. Implant Dent 2002;11(3):286-292 